\title{
RESEARCH
}

Open Access

\section{cxcl12-engineered endothelial progenitor cells enhance neurogenesis and angiogenesis after ischemic brain injury in mice}

Yaning Li ${ }^{1}$, Shuang Chang ${ }^{1}$, Wanlu Li ${ }^{1}$, Guanghui Tang ${ }^{1}$, Yuanyuan $\mathrm{Ma}^{2}$, Yanqun Liu², Fang Yuan ${ }^{1}$, Zhijun Zhang ${ }^{1}$, Guo-Yuan Yang ${ }^{1,2^{*}}$ and Yongting Wang ${ }^{1 *}$ (D)

\begin{abstract}
Background: Ischemic stroke causes a multitude of brain damage. Neurovascular injury and myelin sheath degradation are two manifestations of ischemic brain damage. Therapeutic strategies aiming only at repairing the neural components or the vessels cannot efficiently restore neurological function. Endothelial progenitor cells (EPCS) have the advantages of both promoting angiogenesis and secreting trophic factors that would promote neurogenesis. Chemokine cxcl12 gene therapy has also been shown to promote angiogenesis, neurogenesis, and remyelination, attracting EPCs, neural progenitor cells, and oligodendrocyte progenitor cells (OPCs) to the injured sites of the brain. In this work, we tested whether these two therapeutics can be combined by genetically engineering the EPCs with cxcl12 to harness the synergistic effects of these two interventions.
\end{abstract}

Methods: We used lentivirus (LV) to deliver cxc/12 gene into human umbilical cord blood EPCs to generate the engineered CXCL12-EPCS, which were then delivered into the perifocal region at 1 week after permanent middle cerebral artery occlusion to investigate the effects of CXCL12-EPCs on the functional recovery and angiogenesis, neurogenesis, and remyelination in ischemic stroke mice. Green fluorescent protein (gfp) gene-modified EPCs and LV-CXCL12 gene therapy were used as controls.

Results: CXCL12-EPC treatment significantly reduced brain atrophy and improved neurobehavioral function at 5 weeks after brain ischemia. The treatment resulted in increased blood vessel density and myelin sheath integrity, and promoted neurogenesis, angiogenesis, and the proliferation and migration of OPCs. In-vitro data showed that CXCL12-EPCs performed better in proliferation and tube formation assays and expressed a higher level of vascular endothelial growth factor compared to GFP-EPCS.

Conclusions: The synergistic treatment of CXCL12-EPCs outperformed the single therapies of GFP-EPCs or LVCXCL12 gene therapy in various aspects related to post-ischemic brain repair. cxcl12-engineered EPCs hold great potential in the treatment of ischemic stroke.

\footnotetext{
* Correspondence: gyyang0626@163.com; ytwang@sjtu.edu.cn

${ }^{1}$ School of Biomedical Engineering and Shanghai Jiao Tong University,

Affiliated Sixth People's Hospital, Shanghai Jiao Tong University, 1954 Hua

Shan Road, Shanghai 200030, China

Full list of author information is available at the end of the article
}

(c) The Author(s). 2018 Open Access This article is distributed under the terms of the Creative Commons Attribution 4.0 International License (http://creativecommons.org/licenses/by/4.0/), which permits unrestricted use, distribution, and reproduction in any medium, provided you give appropriate credit to the original author(s) and the source, provide a link to the Creative Commons license, and indicate if changes were made. The Creative Commons Public Domain Dedication waiver (http://creativecommons.org/publicdomain/zero/1.0/) applies to the data made available in this article, unless otherwise stated. 


\section{Background}

Cerebral ischemia causes a cascade of detrimental events, including excitotoxicity, peri-infarct polarization, bloodbrain barrier impairment, inflammation, and apoptosis, resulting in a multitude of injuries among which neurovascular damage and myelin sheath degradation are two signature events [1-4], which together result in failed or false signal transduction at the cellular level, consequently causing the various deficits of neural behavioral function in patients. Angiogenesis, neurogenesis, remyelination, and neuroplasticity are very critical components of functional recovery. Efficient recovery of neurological functions requires consideration of both the neural and vascular components. The stroke pathology is a long process, with increased cell death as early as $30 \mathrm{~min}$, and persists for 4 weeks after ischemic injury as evidenced by DNA fragmentation [5]. MRI parameters also showed that the new lesion area, which presents the damaged brain area emerging 1 day after ischemia, continues to increase until about 6 months post ischemia [6]. Compared to the relatively narrow treatment window of thrombolytic tissue plasminogen activator (tPA) [7] and endovascular thrombectomy, the longer subacute phase presents additional opportunities for intervention.

Endothelial progenitor cells (EPCs) were first isolated in 1997 and found to incorporate into sites with active angiogenesis [8]. The increase of blood circulating EPCs after acute ischemic stroke is associated with preferred functional outcomes and reduced infarction [9]. The lowered number of EPCs is an independent risk factor for poor outcome in patients with acute ischemic stroke [10, 11]. These findings suggest that EPCs may participate in brain repair after ischemic stroke. Previous studies have shown that systemic delivery of EPCs protects the brain against ischemic injury, promotes neurovascular repair, and improves long-term neurobehavioral outcomes [12-14]. During EPC-mediated neuroprotection, chemokine CXCL12 has been shown to play critical roles [15].

Chemokine CXCL12, also known as stromal derived factor-1, was first found to attract early-stage B-cell precursors by binding with its receptor CXCR4 [16]. CXCL12 mediates vascular development by homing circulating EPCs to the site of active angiogenesis and vasculogenesis [17-19]. CXCL12 is a key regulator in the development of the nervous system, mainly by attracting the migration of CXCR4expressing neural progenitor cells (NPCs) and guiding axon growth [20-22]. During myelination and remyelination processes in the embryonic and postnatal central nervous system, CXCL12 also plays important roles in regulating the survival and outward migration of oligodendrocyte progenitor cells (OPCs) [23-26]. In vitro, CXCL12 has been shown to attenuate the apoptosis of EPCs in serum starvation conditions [27, 28], and prevent EPC senescence and enhance reendothelialization in injured arteries [29]. These data suggest that EPCs and CXCL12 both hold the potential to treat brain injury.

Previous work demonstrated that both EPC therapy and $\operatorname{cxcl} 12$ gene therapy yielded positive results in ischemic stroke mice models $[14,30]$. In addition, we also observed that $\operatorname{cxcl12}$ modification of EPCs improved their proliferation and tube formation [31]. Gene engineering of stem cells has been shown to augment their regenerative abilities. The recent clinical trials using modified bone marrow-derived mesenchymal stem cells in the recovery phase also yielded promising outcomes [32]. We hypothesized that $\mathrm{cxcl12}$ engineering of EPCs will afford synergistic effect in improving stroke outcomes.

In this work, we investigated the treatment efficacy of CXCL12-EPCs in the permanent middle cerebral artery occlusion model (pMCAO) of mice. We used lentivirus to engineer EPCs with the cxcl12 gene or gfp gene. We then delivered CXCL12-EPCs, GFP-EPCs (as stem cell therapy control), LV-CXCL12 (as gene therapy control), and PBS (as vehicle control) into the perifocal area through stereotactic injection at 1 week after pMCAO. The effects of CXCL12-EPC treatment on the functional recovery, angiogenesis, neurogenesis, and remyelination were investigated.

\section{Methods}

\section{Experimental protocol}

A total of 58 adult male Institute of Cancer Research (ICR) mice underwent pMCAO surgery. Animals were trained on rotarod for 3 consecutive days before $\mathrm{MCAO}$ surgery. Thirty-nine of them survived MCAO beyond 1 week. Three animals were excluded due to the lack of obvious neurological deficit. Thirty-six animals with similar modified neurological severity score (mNSS) at 7 days after surgery were randomly assigned into four different treatment groups, with 11 mice in the PBS group, nine mice in the LV-CXCL12 group, eight mice in the GFP-EPC group, and eight mice in the CXCL12EPC group. At 7 days after pMCAO surgery, the ischemic mice received either PBS, LV-CXCL12, GFP-EPCs, or CXCL12-EPCs via stereotactical injection into the perifocal region. The mNSS and rotarod performance were followed for 5 weeks after pMCAO. BrdU (Sigma, St. Louis, MO, USA) dissolved in normal saline at a concentration of $10 \mathrm{mg} / \mathrm{ml}$ was injected intraperitoneally at a dose of $50 \mathrm{mg} / \mathrm{kg}$ each day from 28 to 35 days after pMCAO for 7 consecutive days before the animals were sacrificed at 5 weeks.

pLV-CXCL12-IRES-GFP vector construction and LV-CXCL12 production

pLV-CXCL12-IRES-GFP vector was subcloned by inserting mouse $\operatorname{cxcl} 12$ cDNA into the multiple-cloning site of pLVIRES-GFP plasmid. pLV-CXCL12-GFP was cotransfected 
with pVSVG and pDelta plasmids into $293 \mathrm{~T}$ cells by calcium phosphate precipitation (Fig. 1A). The viruses were further purified by density gradient ultracentrifugation in $20 \%$ sucrose in PBS. LV-GFP was simultaneously prepared as control following a published protocol [33].

\section{EPC isolation and identification}

EPCs were isolated from human umbilical cord blood obtained from the International Peace Maternity and Child Health Hospital, Shanghai, China. This procedure was approved by the Ethics Committee of Shanghai Jiao Tong University, Shanghai, China. EPC isolation and identification were carried out as described previously $[13,31]$ and characterized similar to that reported by other groups [34]. Briefly, monocytes were isolated from umbilical cord blood by centrifugation with lymphocyte separation medium (MP Biomedicals, Santa Ana, CA, USA) and washed twice with M199 medium (Hyclone, Logan, UT, USA). The cells were resuspended in EGM-2 Bullet kit medium (Lonza, Anaheim, CA, USA), seeded in a six-well plate $\left(1 \times 10^{7}\right.$ cells per well) coated with human fibronectin (Sigma), and incubated at $37{ }^{\circ} \mathrm{C}$ with $5 \% \mathrm{CO}_{2}$. After growing to about $80 \%$ confluence, the cells were trypsinized and passaged.

The EPCs were identified by flow cytometry (FACScalibur; BD Biosciences, Franklin Lakes, NJ, USA). For this purpose, EPCs were incubated with fluorescent antibodies of CD31-PE, CD34-PE (eBioscience, San Diego,

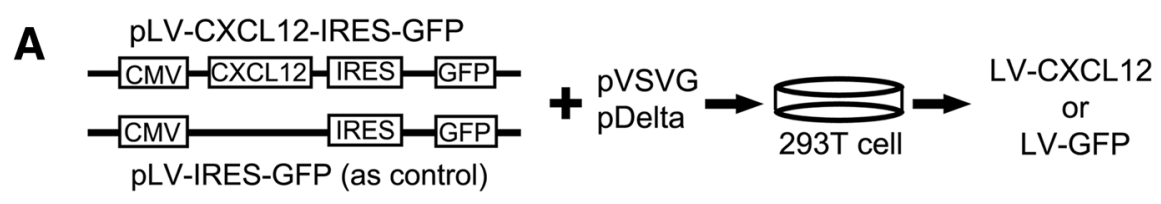

B

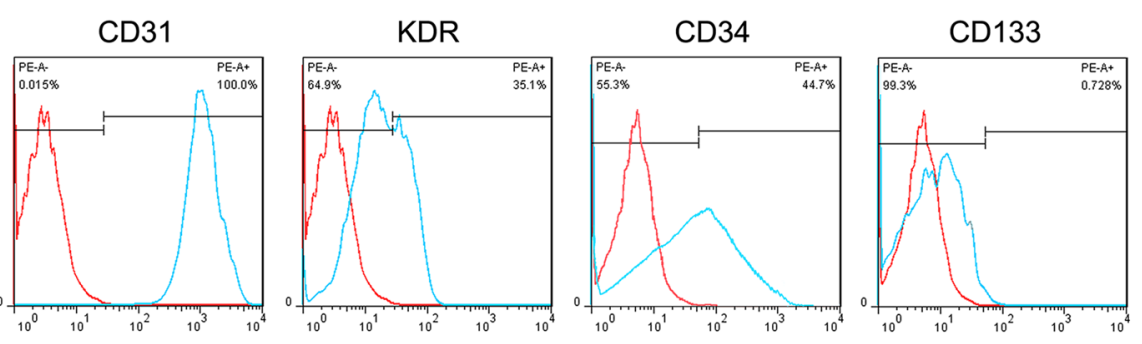

C
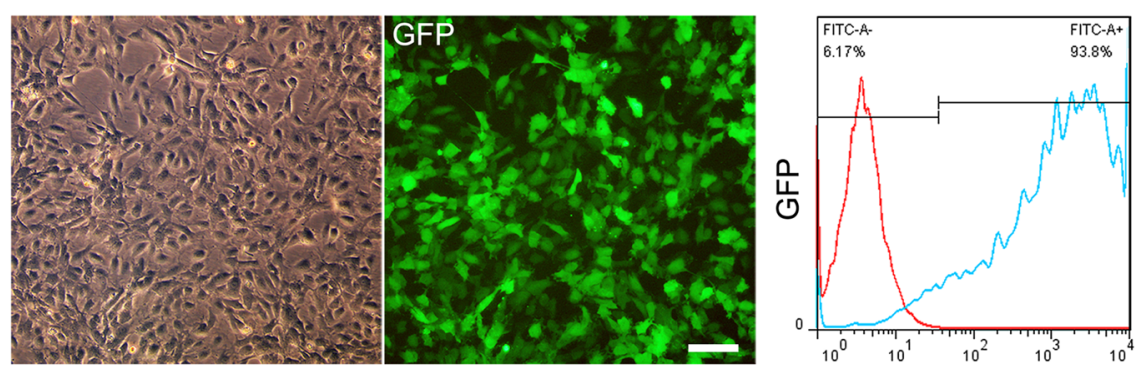

D a

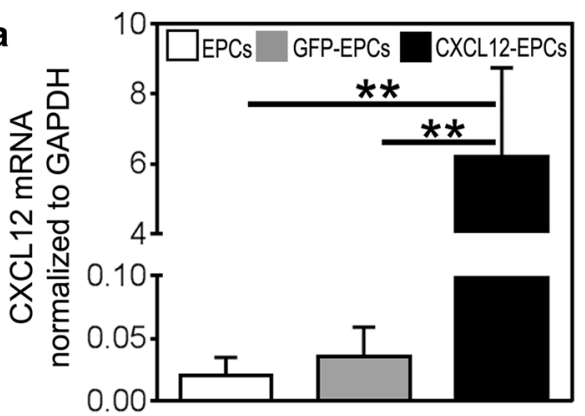

b

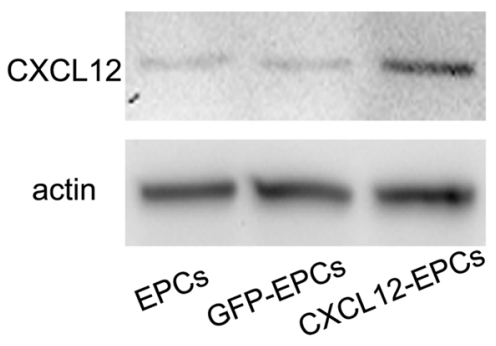

Fig. 1 LV-CXCL12 virus successfully transfected EPCS in vitro. A Clone of pLV-CXCL12-IRES-GFP plasmid by inserting mouse CXCl12 CDNA sequence in pLV-IRES-GFP plasmid, then cotransfected 293 T cells with pVSVG and pDelta plasmid to package LV-CXCL12 and LV-GFP virus. B Flow cytometry to characterize human umbilical cord blood-derived EPCs by cell surface markers CD31, KDR, CD34, and CD133. C LV-CXCL12-transfected EPCs in bright field (left), fluorescent field (middle), and flow cytometry (right) to identify transfection efficacy of CXCL12-EPCs. Scale bar: $100 \mu \mathrm{m}$. D Real-time PCR and western blot analysis to detect CXCL12 mRNA (a) and protein (b) expression in EPCs, GFP-EPCs, and CXCL12-EPCs. $n=3$, technical replica. Data presented as mean \pm SD. ${ }^{* *} p<0.01$. GFP green fluorescent protein, EPC endothelial progenitor cells, GFP-EPC endothelial progenitor cell modified by gfp gene, CXCL12-EPC endothelial progenitor cell modified by cxcl12 gene 
CA, USA), KDR-PE (BD Biosciences), or CD133-PE (Miltenyi Biotec, Shanghai, China) in the dark for $30 \mathrm{~min}$, and washed twice by PBS before being loaded onto the FACS for analysis.

EPCs at $80 \%$ confluence were transfected with LVCXCL12 (CXCL12-EPCs) or LV-GFP (GFP-EPCs) at the third passage. The transfection efficiency was identified by flow cytometry for GFP-positive cells. All experiments were performed using the fifth passage of EPCs.

\section{EPC proliferation and tube formation assay}

EPC proliferation was examined using the cell counting kit-8 (CCK-8; Dojindo, Kumamoto, Japan) [35]. EPCs $\left(1 \times 10^{4}\right.$ cells), GFP-EPCs, and CXCL12-EPCs were incubated with the mixture of CCK- 8 and EGM- 2 medium (1:10) for $5 \mathrm{~h}$ in a 96-well plate. The media absorbance at $450 \mathrm{~nm}$ was then recorded using a micro-plate reader (BioTek, Chicago, IL, USA). Blank control was set by the absorption of the medium only.

The EPC tube formation assay was performed as described previously [13]. Matrigel (50 $\mu$; BD Biosciences) was added to a 96-well plate and allowed to solidify at $37{ }^{\circ} \mathrm{C}$ for $30 \mathrm{~min}$. Then $1 \times 10^{4}$ EPCs, GFP-EPCs and CXCL12-EPCs were suspended in $100 \mu \mathrm{l}$ EGM-2 medium and seeded in the matrigel-coated plate. After incubating for $6 \mathrm{~h}$, the plate was examined with a microscope (Leica, Solms, Germany). The tube number in each well was counted by an investigator blind to the sample designation.

\section{CXCL12 and VEGF real-time polymerase chain reaction quantification}

Total RNA from the EPCs, GFP-EPCs, and CXCL12EPCs were isolated using TRIzol reagent (Invitrogen, Carlsbad, CA, USA) and suspended in $40 \mu \mathrm{l}$ of RNasefree water according to the manufacturer's protocol. The amplification was performed by a fast-real-time polymerase chain reaction (PCR) system $(7900 \mathrm{HT}$; ABI, Foster, CA, USA) using a SYBR Premix Ex Taq Kit (Takara, Dalian, China). CXCL12 and VEGF mRNA levels were normalized to the endogenous control GAPDH expression in triplicate. The primers used were as follows: mouse CXCL12, forward TGCATCAGTGACGGTAAACCA and reverse CACAGTTTGGAGTGTTGAGGAT; human VEGF, forward GAGGAGCAGTTACGGTCTGTG and reverse TCCTTTCCTTAGCTGACACTTGT; and human GAPDH, forward CTGGGCTACACTGAGCACC and reverse AAGTGGTCGTTGAGGGCAATG.

\section{CXCL12 and VEGF western blot assay}

Proteins were extracted separately from EPCs, GFPEPCs, and CXCL12-EPCs with RIPA (Millipore, Temecula, CA, USA). The western blot protocol was carried out as described previously [36]. The primary antibodies were CXCL12 and VEGF (1:1000; Abcam, Cambridge, MA, USA), and $\beta$-actin (1:1000; Santa Cruz Biotechnology, Santa Cruz, CA, USA).

\section{Permanent middle cerebral artery occlusion in mice} Adult male ICR mice (Sippr-bk, Shanghai, China) weighing $30 \pm 2 \mathrm{~g}$ were anesthetized by ketamine/xylazine (100/10 mg/kg; Sigma-Aldrich, St Louis, MO, USA). MCAO was carried out as described previously [30]. Briefly, after isolation of the common carotid artery and external and internal carotid arteries, the left MCA was occluded by inserting a 6-0 nylon suture coated with silica gel. Body temperature was maintained at $37{ }^{\circ} \mathrm{C}$ throughout the surgery using a thermal blanket. Successful occlusion was verified by laser Doppler flowmetry (Moor Instruments, Axminster, UK).

\section{Neurobehavioral tests}

An investigator blind to the experimental design carried out a rotarod test and neurological evaluations using the mNSS. Baseline values were generated by selecting a maximum of six trials before surgery. Rotarod test data were analyzed using the same method as that of the baseline values. Mice were examined up to 5 weeks after pMCAO. The rotarod test required mice to balance on a rotating rod. Mice were allowed 1 min for adaption on the rod, after which the rod was accelerated to $40 \mathrm{rpm}$ over $2 \mathrm{~min}$ and the time spent on the rod was recorded. The mNSS of the animals was graded on a scale of $0-18$, which is a composite of motor, reflex, and balance tests [37].

\section{LV-CXCL12 viral vector injection and GFP/CXCL12-EPC transplantation}

One week after pMCAO, the mice were anesthetized and immobilized on a stereotaxic frame (RWD Life Science, Shenzhen, China). A total volume of $10 \mu \mathrm{l}$ of PBS containing $5 \times 10^{7}$ LV-CXCL12 viral particles or $3 \times 10^{5}$ GFP/CXCL12-EPCs were injected stereotactically at a rate of $500 \mathrm{nl} / \mathrm{min}$ at $2 \mathrm{~mm}$ lateral to the bregma and $3 \mathrm{~mm}$ under the dura. The needle was maintained for $10 \mathrm{~min}$ before withdrawal. The bone hole was sealed with bone wax and the wound was stitched. After awakening from anesthesia, the mice were returned to their cages for long-term recovery.

\section{Brain atrophy measurement}

Brains were removed and frozen immediately after sacrificing the mice. A series of $20-\mu \mathrm{m}$ coronal sections 1.3 $\mathrm{mm}$ to $-2.7 \mathrm{~mm}$ from the bregma were cut and mounted on glass slides. The sections were stained using a cresyl violet solution. The atrophic area was calculated by subtracting the cresyl violet stained area in the ipsilateral hemisphere from the whole area of the contralateral 
hemisphere using ImageJ software (NIH, USA). The atrophy volume was calculated using the formula $\sum_{1}^{n}\left[\left(S_{n}\right.\right.$ $\left.\left.+\sqrt{S_{n} * S_{n+1}}+S_{n+1}\right) * \frac{h}{3}\right]$, where $S$ represents the atrophic area $\left(\mathrm{mm}^{2}\right)$ in each brain section and $h$ represents the distance between adjacent brain slices that were stained, here $h=0.2 \mathrm{~mm}$.

\section{Immunohistochemistry}

Brains were post-fixed for $4-5 \mathrm{~h}$ followed by $24 \mathrm{~h}$ of immersion in 30\% sucrose in PBS, immediately frozen, and then sectioned using a cryostat (Leica, Solms, Germany). Then $20-\mu \mathrm{m}$ coronal sections were cut. Floating coronal sections were collected in antigen protective solution, which contains 50\% PBS, 30\% glycerol, and 20\% glycol.

Immunohistochemistry was performed according to the protocol described previously [30]. Care was taken to sample sections with similar anatomical features. The primary antibodies were: CD31 (1:200 dilution; R\&D Systems, Minneapolis, MN, USA); NeuN (1:100 dilution) and platelet-derived growth factor $\alpha$ (PDGFR $\alpha ; 1: 200$ dilution) (Millipore, Billerica, MA, USA); BrdU and DCX (1:200 dilution; Santa Cruz Biotechnology); and myelin basic protein (MBP; 1:300 dilution) (Abcam).

For BrdU staining, sections were first treated with $2 \mathrm{~mol} / \mathrm{L} \mathrm{HCl}$ for $30 \mathrm{~min}$ at $37{ }^{\circ} \mathrm{C}$ and then neutralized

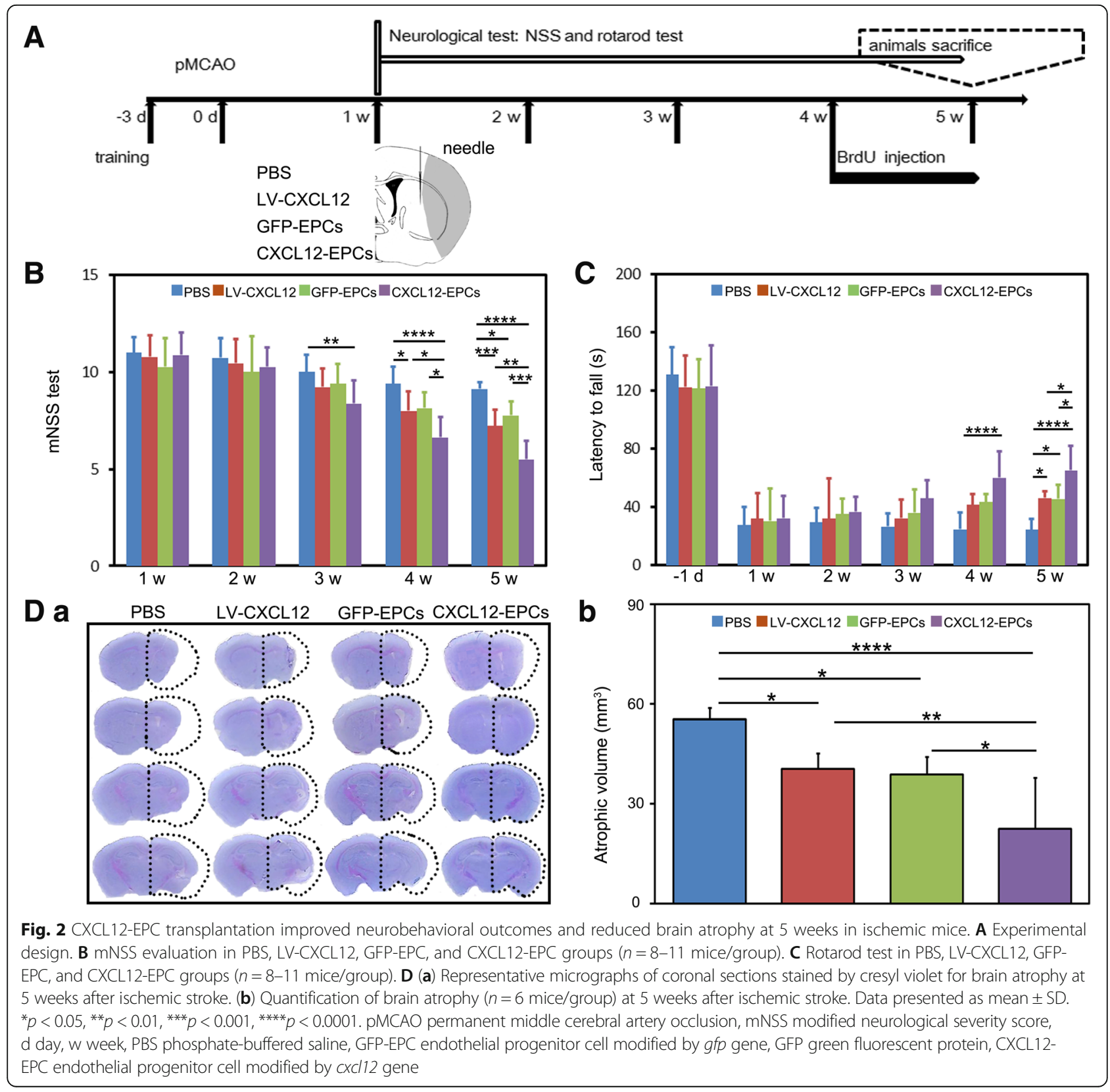



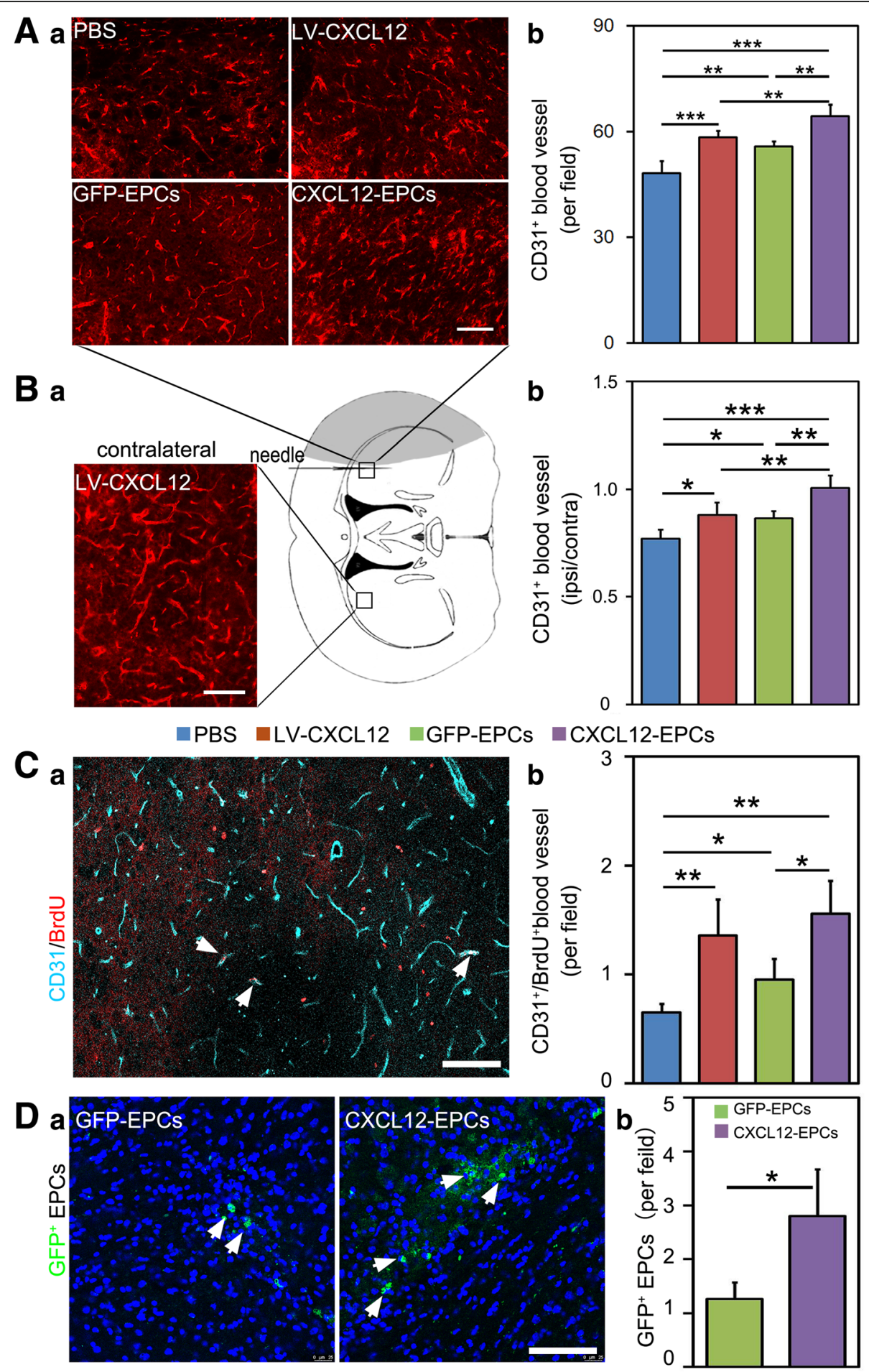

Fig. 3 (See legend on next page.) 
(See figure on previous page.)

Fig. 3 CXCL12-EPC transplantation increased blood vessel density and promoted angiogenesis in ischemic mouse brain. A (a) Photomicrographs of CD31 $1^{+}$microvessels in ipsilateral hemisphere in PBS, LV-CXCL12, GFP-EPC, and CXCL12-EPC groups at 5 weeks after MCAO. (b) Quantification of $\mathrm{CD} 31^{+}$microvessels in perifocal region 5 weeks after MCAO. B (a) Representative photomicrographs of CD $31^{+}$microvessels in contralateral hemisphere. Hollow box in brain diagram shows area of interest at 5 weeks after MCAO. (b) Ratio of ipsilateral/contralateral CD $31^{+}$microvessels at 5 weeks after MCAO. C (a) Representative photomicrographs of CD31 and BrdU immunostaining of ipsilateral hemisphere at 5 weeks after MCAO. Arrows indicate $\mathrm{CD} 31^{+} / \mathrm{BrdU}^{+}$colocalized newly formed microvessels. (b) Quantification of $\mathrm{CD} 31^{+} / \mathrm{BrdU}^{+}$newly formed microvessels in ipsilateral hemisphere at 5 weeks after MCAO. D (a) Representative image of GFP ${ }^{+}$cells (white arrows) from GFP-EPC and CXCL12-EPC therapy mouse brain 4 weeks after transplantation. (b) Quantification of GFP ${ }^{+}$EPCs in ipsilateral hemisphere in GFP-EPC and CXCL12-EPC-treated group 4 weeks after transplantation. Scale bar: $100 \mu \mathrm{m} . n=3-4$ mice/group. Data presented as mean \pm SD. ${ }^{*} p<0.05,{ }^{* *} p<0.01,{ }^{* * *} p<0.001$. All markers presented by pseudo colors. PBS phosphate-buffered saline, GFP-EPC endothelial progenitor cell modified by gfp gene, GFP green fluorescent protein, CXCL12-EPC endothelial progenitor cell modified by cxCl12 gene

twice with $0.1 \mathrm{~mol} / \mathrm{L}$ sodium borate $(\mathrm{pH} 8.5)$ for $10 \mathrm{~min}$ each. Sections were then treated with $0.3 \%$ Triton-100 in PBS for $10 \mathrm{~min}$, blocked by 5\% normal donkey serum, and incubated with anti-BrdU and anti-DCX (or antiNeuN or anti-CD31) antibody at $4{ }^{\circ} \mathrm{C}$ overnight. Finally, the sections were incubated with proper secondary antibodies for $60 \mathrm{~min}$ at room temperature. Stained sections were mounted after rinsing. For biotinylated immunostaining, the brain sections incubated with the same primary antibodies were developed for the same amount of time.

\section{Cell and vessel counting}

Four fields were selected randomly from the perifocal region at $\times 20$ or $\times 40$ objective. $\mathrm{DCX}^{+} / \mathrm{BrdU}^{+}$and PDGFR $\alpha$ cells in the subventricular zone (SVZ) were counted for each image (DM2500; Leica Microsystems, Wetzlar, Germany). Sections incubated with the same primary antibodies were imaged under the same conditions by an investigator blind to sample designation. The quantity of $\mathrm{BrdU}^{+}, \mathrm{DCX}^{+} / \mathrm{BrdU}^{+}, \mathrm{NeuN}^{+} / \mathrm{BrdU}^{+}$, PDGFR $\alpha^{+}$cells, $\mathrm{CD}^{+} 1^{+}$and $\mathrm{CD} 31^{+} / \mathrm{BrdU}^{+}$microvessels in the ipsilateral hemisphere were counted and quantified by an investigator blind to the experimental groups in the same manner. Four serial sections, spaced $400 \mu \mathrm{m}$ apart (1.10 $\mathrm{mm}$ to $-0.1 \mathrm{~mm}$ from the bregma), were selected from each animal.

\section{Integral optical density of $\mathrm{MBP}^{+}$myelin sheath fluorescence}

MBP staining intensity was computed as the mean integrated optical density (IOD) as described previously [38]. Briefly, four fields were randomly selected from the perifocal region at $\times 20$ objective (DM2500; Leica Microsystems) under the same conditions. The images were automatically analyzed by the "Pathology" function of Image Pro Plus 6.0 (Media Cybernetics, Bethesda, MD, USA) for quantitative analysis, where IOD was calculated for arbitrary areas. Brain sections not incubated in the primary antibody were used to estimate the background staining. Four serial sections, spaced $400 \mu \mathrm{m}$ apart, were selected from each animal and there were four animals in each group. The results were normalized to the IOD of PBS group.

\section{Statistical analysis}

Parametric data analysis for the mNSS and the rotarod test was performed by repeated-measured two-way ANOVA followed by Tukey's test. For nonrepeated data analysis, one-way ANOVA followed by Tukey's test was used for three groups or more, and Student's $t$ test was performed for two groups using GraphPad Prism version 6.02 (GraphPad Software, Inc., La Jolla, CA, USA). All data were presented as mean \pm SD. A probability value of $p<0.05$ was considered statistically significant.

\section{Results}

LV-CXCL12 virus successfully transfected EPCs in vitro

To modify EPCs with the cxcl12 gene in vitro, we constructed pLV-CXCL12-IRES-GFP plasmid by inserting cxcl12 cDNA into pLV-IRES-GFP plasmid. pLVCXCL12-IRES-GFP or pLV-IRES-GFP plasmid was used to cotransfect 293 T cells with pVSVG and pDelta plasmids to produce LV-CXCL12 and LV-GFP (as control) (Fig. 1A). Flow cytometry analysis showed that the isolated cells were approximately 100\% CD31-positive, 35.1\% KDR-positive, 44.7\% CD34-positive, and 0.728\% CD133positive (Fig. 1B), which demonstrated that these isolated cells were EPCs. LV-CXCL12 virus efficiently transfected EPCs, with 93.8\% cells being GFP-positive (Fig. 1C). Further, real-time PCR and western blot analysis showed that the expression of CXCL12 both at mRNA and protein levels were significantly increased in CXCL12-EPCs compared to EPCs and GFP-EPCs (Fig. 1D). The gene-modified CXCL12-EPCs, GFP-EPCs (as stem cell control), and LVCXCL12 virus (as gene therapy control) were used in the following experiments.

\section{CXCL12-EPC transplantation improved neurobehavioral outcomes and reduced brain atrophy in ischemic mice} The experimental plan is illustrated in Fig. 2A. To evaluate the roles of CXCL12-EPC transplantation in neurological outcomes, neurological assessments including the mNSS and the rotarod test were carried out for up to 5 weeks 


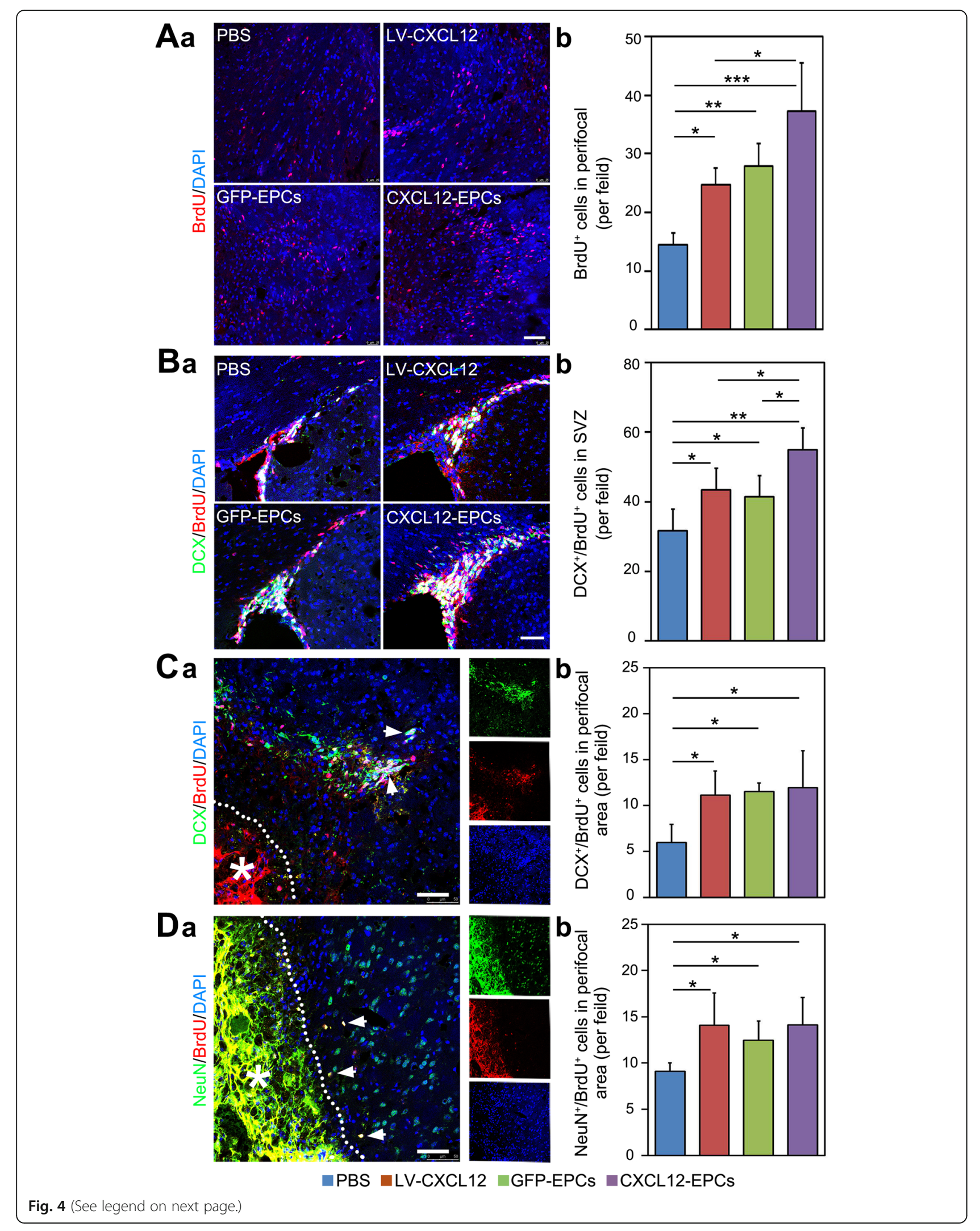


(See figure on previous page.)

Fig. 4 CXCL12-EPC transplantation promoted neurogenesis in ischemic mouse brain. A (a) BrdU staining and (b) quantification of BrdU $U^{+}$cells in perifocal area at 5 weeks after MCAO. B (a) Double immunostaining of DCX and BrdU-positive cells and (b) quantification of $\mathrm{DCX}^{+} / \mathrm{BrdU}^{+}$cells in the SVZ at 5 weeks after MCAO. C (a) Double immunostaining of DCX and BrdU cells (white arrows) and (b) quantification of DCX $/ \mathrm{BrdU}^{+}$cells in perifocal region of ipsilateral hemisphere at 5 weeks after MCAO. D (a) Double immunostaining of NeuN and BrdU (white arrows indicate double positive cells) and (b) quantification of $\mathrm{NeuN}^{+} / \mathrm{BrdU}^{+}$cells in perifocal region of ipsilateral hemisphere 5 weeks after MCAO. $n=3-4$ mice/group. Scale bar: $50 \mu \mathrm{m}$. Data presented as mean $\pm \mathrm{SD} .{ }^{*} p<0.05,{ }^{* *} p<0.01$. All markers presented by pseudo colors. PBS phosphate-buffered saline, GFP-EPC endothelial progenitor cell modified by gfp gene, GFP green fluorescent protein, CXCL12-EPC endothelial progenitor cell modified by cxcl12 gene, SVZ subventricular zone

after pMCAO. The mNSS was significantly improved in the gene therapy and stem cell therapy groups at 5 weeks after ischemia compared to the PBS group $(9.13 \pm 0.35)$, with a better outcome in the CXCL12-EPC group (5.50 \pm 0.93) compared to the LV-CXCL12 gene therapy group $(7.22 \pm 0.83)$ and the GFP-EPC cell therapy group $(7.75 \pm$ 0.71 ) (Fig. 2B). In parallel, the rotarod test showed that the motor function greatly improved in all therapeutic groups at 5 weeks after ischemia compared to the PBS group (24.63 $\pm 7.54 \mathrm{~s}$ ), with a better improvement in the CXCL12-EPC group (65.25 $\pm 16.82 \mathrm{~s})$ compared to the LV-CXCL12 group $(46.22 \pm 4.99 \mathrm{~s})$ and the GFP-EPC group $(45.75 \pm 9.60$ s) (Fig. 2C). Furthermore, we characterized whether CXCL12-EPC transplantation protected the brain from injury and found that the brain atrophy volume was reduced in the LV-CXCL12 $\left(81.23 \pm 9.16 \mathrm{~mm}^{3}\right)$, GFP-EPC $\left(77.54 \pm 10.91 \mathrm{~mm}^{3}\right)$, and CXCL12-EPC $\left(44.83 \pm 31.17 \mathrm{~mm}^{3}\right)$ therapy groups compared to the PBS group $\left(110.93 \pm 6.79 \mathrm{~mm}^{3}\right)$, with a smaller atrophic volume in the CXCL12-EPC group compared to the GFP-EPC and LV-CXCL12 treatment groups (Fig. 2D).

\section{CXCL12-EPC transplantation increased blood vessel density} and promoted angiogenesis in ischemic mouse brain

CD31 immunostaining was performed to examine the blood vessel density after treatment. The density of CD31 ${ }^{+}$ blood vessels in the perifocal area was significantly higher in all therapeutic groups compared to the PBS group, with more $\mathrm{CD}_{31}{ }^{+}$blood vessels in the CXCL12-EPC cell therapy group compared to the LV-CXCL12 and GFP-EPC groups (Fig. 3A). The ratios of blood vessel in ipsilateral to contralateral hemisphere were also higher in all therapeutic groups compared to the PBS group, with the highest $\mathrm{CD}_{3} 1^{+}$blood vessel ratio in the CXCL12-EPC cell therapy group (Fig. 3B). We further examined whether CXCL12-EPC promoted angiogenesis by performing CD31 and BrdU double immunostaining. Data showed that the number of $\mathrm{CD} 1^{+} / \mathrm{BrdU}^{+}$blood vessels was increased in all therapeutic groups compared to the PBS group, with more $\mathrm{CD} 1^{+} / \mathrm{BrdU}^{+}$blood vessels in the CXCL12-EPC group compared to the GFP-EPC group (Fig. 3C), which indicated that the transplantation of CXCL12-EPCs not only increased blood vessel intensity, but also promoted angiogenesis in ischemic mouse brain.
The transplanted CXCL12-EPCs exhibited a better cell viability in ischemic mouse brain than GFP-EPCs, which were supported by higher numbers of GFP-positive cells in the ischemic mouse brain in the CXCL12-EPC group at 4 weeks after transplantation (Fig. 3D).

\section{CXCL12-EPC transplantation promoted neurogenesis in ischemic mouse brain}

The neuroblasts migrate close to blood vessels, and vasculature plays an important role for long-term neurogenesis, so the optimization of vascularization may promote neurogenesis after stroke [39]. BrdU staining were performed to show that the number of newly born cells in treatment groups were significantly increased compared to the PBS control group at 5 weeks after pMCAO, with even higher number of $\mathrm{BrdU}^{+}$cells in the CXCL12-EPC treatment group than the LV-CXCL12 treatment group (Fig. 4A). To analyze whether the transplantation of CXCL12-EPCs promoted focal neurogenesis, which facilitates functional recovery after ischemia [40], double immunostaining of DCX and BrdU was performed. The number of $\mathrm{DCX}^{+} / \mathrm{BrdU}^{+} \mathrm{NPCs}$ significantly increased in the SVZ in all therapeutic groups compared to the PBS group, with significantly more $\mathrm{DCX}^{+} / \mathrm{BrdU}^{+}$ cells in the CXCL12-EPC group compared to the LVCXCL12 and GFP-EPC group (Fig. 4B), which indicated that CXCL12-EPC transplantation promoted the proliferation of NPCs in SVZ. The process of neurogenesis consists of the proliferation, migration, and maturation of NPCs [41, 42]. Further data showed that the number of $\mathrm{DCX}^{+} / \mathrm{BrdU}^{+} \mathrm{NPCs}$ (Fig. 4C) and $\mathrm{NeuN}^{+} /$ $\mathrm{BrdU}^{+}$newborn neurons (Fig. 4D) in the perifocal area of ischemia were significantly increased in all therapeutic groups compared to the PBS group. These results suggest that CXCL12-EPC transplantation augmented neurogenesis, through promoting NPC proliferation at 4 weeks after transplantation.

\section{CXCL12-EPC transplantation protected myelin sheath integrity in ischemic mouse brain}

To demonstrate whether CXCL12-EPC transplantation protects the myelin sheath integrity, which ensures the correct signal transduction and neuronal conductivity [43, 44], MBP immunostaining for myelin sheath protein was performed. As an indicator of myelin sheath integrity, the 


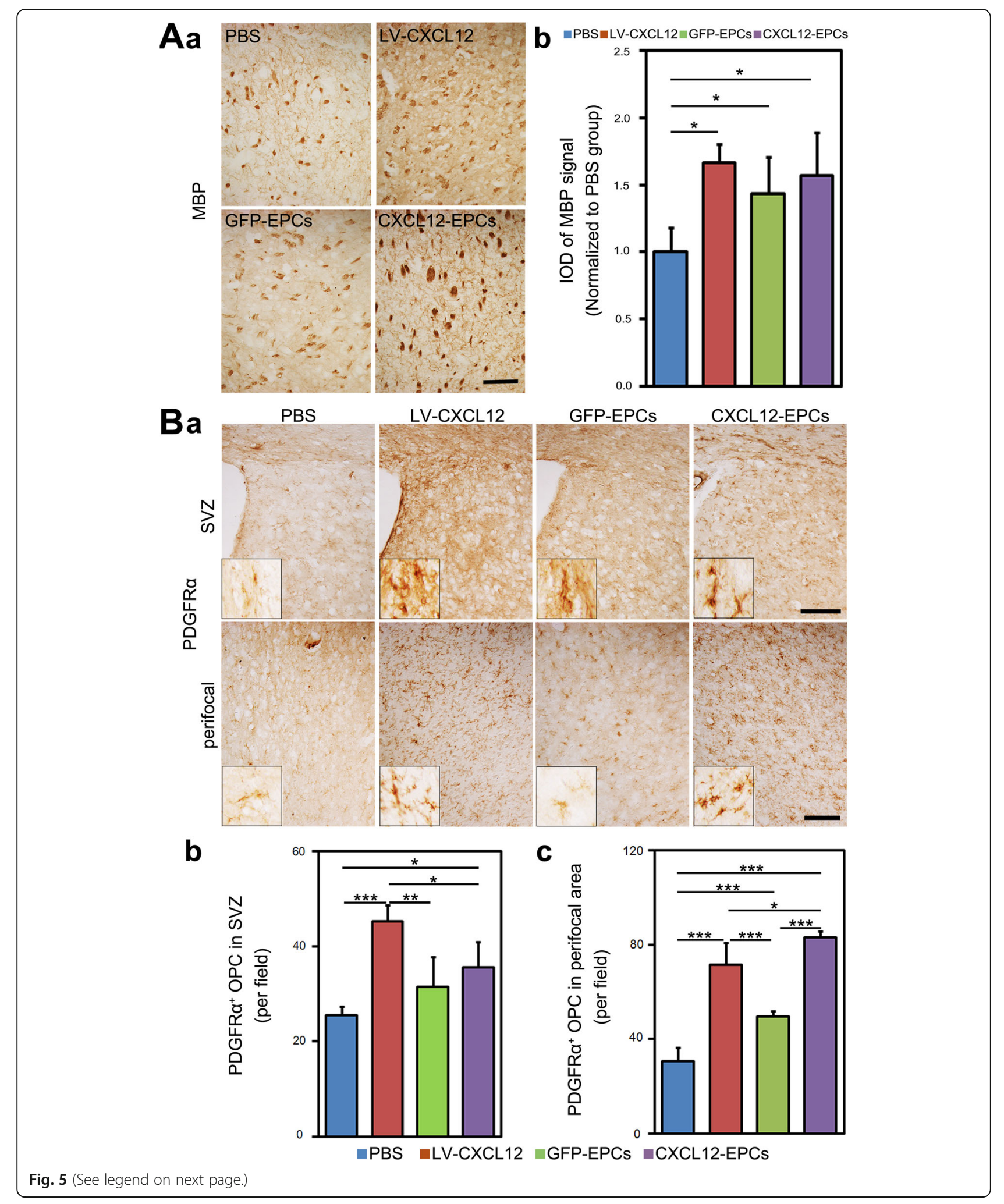


(See figure on previous page.)

Fig. 5 CXCL12-EPC transplantation protected myelin sheath integrity in ischemic mouse brain. A (a) DAB immunostaining of MBP-positive cells and (b) IOD semiquantification of $\mathrm{MBP}^{+}$signal in ipsilateral hemisphere at 5 weeks after MCAO. B (a) DAB immunostaining of PDGFRa-positive cells in SVZ and perifocal area and quantification of PDGFRa ${ }^{+}$cells in (b) SVZ and (c) perifocal area in ipsilateral hemisphere at 5 weeks of ischemic mouse brain. Insets are higher magnifications from corresponding images. $n=4$ mice/group. Scale bar: $100 \mu \mathrm{m}$. Data presented as mean \pm SD. ${ }^{*} p<0.05,{ }^{* *} p<0.01$, ${ }^{* * *} p<0.001$. MBP myelin basic protein, PBS phosphate-buffered saline, GFP-EPC endothelial progenitor cell modified by gfp gene, GFP green fluorescent protein, CXCL12-EPC endothelial progenitor cell modified by CxCl12 gene, IOD integral optical density, PDGFR platelet-derived growth factor receptor, OPC oligodendrocyte progenitor cell, SVZ subventricular zone

MBP intensity of the ipsilateral hemisphere in all therapeutic groups was higher than that in the PBS control group (Fig. 5A). Further, we examined whether CXCL12EPC transplantation influenced the proliferation and migration of OPCs. CXCR4 expression by OPCs has been demonstrated in our previous study, which shows that CXCR4 was expressed abundantly in NG2-positive and/or PDGFR $\alpha$-positive OPCs. OPCs were separately quantified by staining for PDGFR $\alpha^{+}$cells in the SVZ and the perifocal area in the ipsilateral hemisphere. The data showed that the number of PDGFR ${ }^{+}$cells was significantly increased in all therapeutic groups compared to the PBS control group both in the SVZ and the perifocal area, with more PDGFR $\alpha^{+}$cells in the SVZ in the LV-CXCL12 group compared to the GFP-EPC and CXCL12-EPC groups and more PDGFR ${ }^{+}$cells in the perifocal area in the CXCL12-EPC group than the LVCXCL12 and GFP-EPC groups (Fig. 5B). These data indicated that CXCL12-EPC transplantation protected brain myelin sheath integrity and promoted the proliferation and migration of OPCs at 4 weeks after transplantation.

\section{CXCL12-EPCs showed higher proliferation ability, VEGF secretion, and tube formation}

CXCL12-EPCs exhibited higher cell proliferation ability compared to GFP-EPCs and EPCs based on CCK assay performed using cell culture (Fig. 6a). Previous studies showed that the conditional medium of EPCs contains many kinds of growth factors, including VEGF, basic fibroblast growth factor (bFGF), platelet-derived growth factor (PDGF) [45], and brain-derived neurotrophic factor (BDNF), which contribute to its ability to promote adult SVZ neurogenesis [46]. To investigate whether cxcl12 modification of EPCs enhanced the secretion of these trophic factors in vitro, real-time PCR was performed to examine the mRNA expression of VEGF, BDNF, bFGF, and PDGF in EPCs, GFP-EPCs, and CXCL12-EPCs. The result showed that CXCL12-EPCs expressed higher levels only of VEGF mRNA compared to EPCs and GFP-EPCs (Fig. 6b, others not shown). Western blot analysis also identified the increased expression of VEGF protein in CXCL12-EPCs (Fig. 6c). We subsequently examined the tube formation ability of these EPCs on Matrigel. The results revealed that CXCL12-
EPCs have higher tube formation ability compared to EPCs and GFP-EPCs (Fig. 6d).

\section{Discussion}

Ischemic stroke results in the nonselective damage of all cells in the brain, including endothelial cells, neurons, oligodendrocytes, and so forth [1]. Treatment strategies for ischemic stroke after the subacute phase would have a higher chance of success by promoting angiogenesis, neurogenesis, and remyelination simultaneously. In this study, we demonstrated that the transplantation of cxcl12 gene-engineered stem cell CXCL12-EPCs into mouse brain at 1 week after ischemia, a considerably delayed treatment regimen, still significantly improved neural behavioral recovery and reduced brain atrophy at 5 weeks after ischemia. The efficacy of the combined treatment of CXCL12-EPCs is significantly higher compared to the single therapies of GFP-EPC stem cell therapy or LV-CXCL12 gene therapy. This strategy significantly extended the treatment window for ischemic stroke.

Mechanistic investigations showed that CXCL12-EPC transplantation greatly increased the blood vessel density and promoted angiogenesis compared to the PBS control group. By using the average number of blood vessels in the ipsilateral hemisphere and the ratio of the number of blood vessels in the ipsilateral to contralateral hemisphere, we demonstrated that both the average number of blood vessels and the ratio were higher in the CXCL12-EPC group compared to the other groups. For the evaluation of angiogenesis, the brain sections were double stained with anti-CD31 (endothelial cell marker) and BrdU (incorporated into newly formed cell nucleus) antibodies to label newly formed blood vessels. The CD31/BrdU doublepositive cells were considered new sprouts of blood vessels. Comparing the extent of angiogenesis and the increase of blood vessel density, it is obvious that angiogenesis cannot account for the observed blood vessel density increase. One logical explanation is that CXCL12-EPCs also protected vessels from delayed damage.

In addition to a significant increase of angiogenesis and neurogenesis, the proliferation and migration of OPCs were observed in the CXCL12-EPC-treated group. PDGFR $\alpha$ expression has been found on various types of cells. However, in the nontumor central nervous system, most of the PDGFR $\alpha$-positive cells were OPCs, then differentiating into 

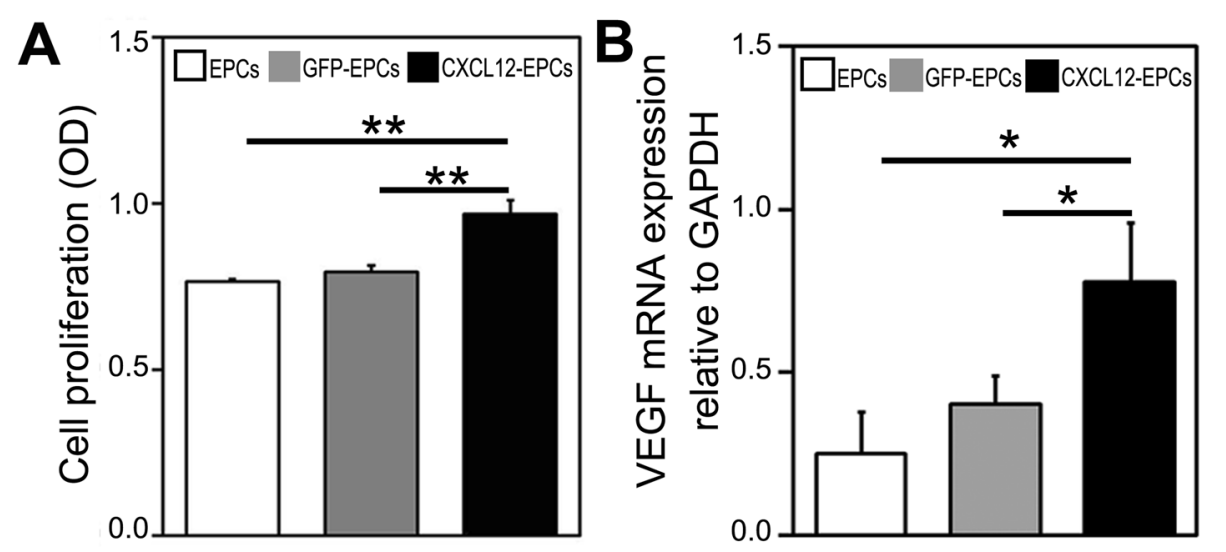

C
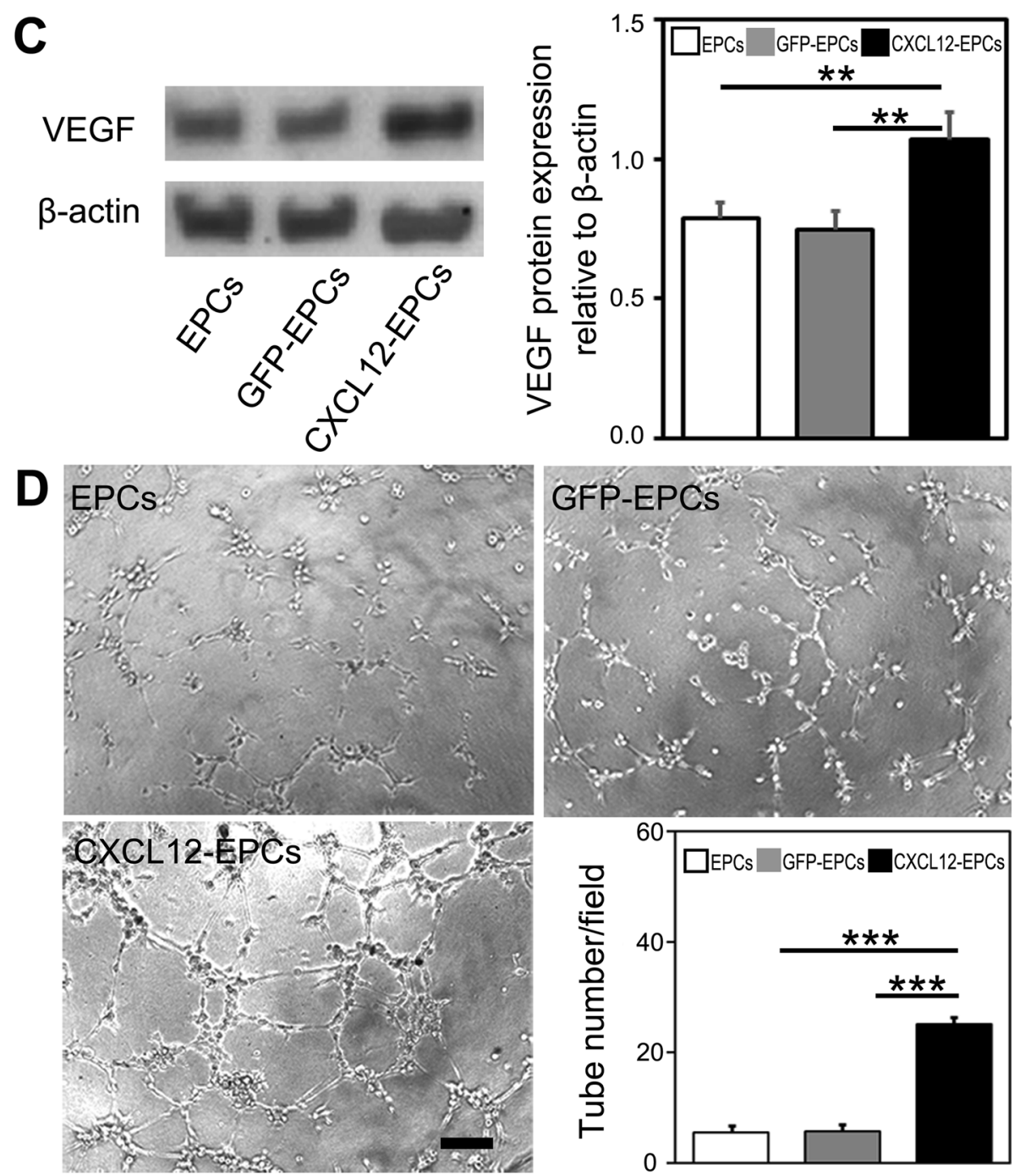

Fig. 6 CXCL12-EPCs showed higher proliferation, VEGF secretion, and tube formation ability. a CXCL12-EPCs held higher cell proliferation ability. b Real-time PCR results show increased expression of VEGF mRNA in CXCL12-EPCs. c Western blot results show increased expression of VEGF protein in CXCL12-EPCs and densitometric analysis of VEGF protein expression. $\mathbf{d}$ Representative images show CXCL12-EPCs had higher tube formation ability. $n=3$, technical replica. Data presented as mean \pm SD. ${ }^{*} p<0.05,{ }^{* *} p<0.01,{ }^{* * *} p<0.001$. OD optical density, EPC endothelial progenitor cell, GFPEPC endothelial progenitor cell modified by gfp gene, GFP green fluorescent protein, CXCL12-EPC endothelial progenitor cell modified by CXCl12 gene, VEGF vascular endothelial growth factor 
oligodendrocytes [47]. Although the highest NPC proliferation was observed with the CXCL12-EPC-treated group, there were no significant differences in the migration and maturation of NPCs in the perifocal region among the three treatment groups. Myelin sheath integrity, as indicated by MBP staining, was also improved by all three treatment regimens without significant differences among the three groups. Studies with longer time course are warranted to further understand the long-term impacts on NPC and OPC migration and maturation by different treatment designs.

In-vitro studies have shown that CXCL12-EPCs presented higher cell proliferation, vascular endothelial growth factor (VEGF) expression, and tube formation ability compared to GFP-EPCs and nonmodified EPCs. In our previous study, it was also shown that CXCL12EPCs have higher migratory capacity than GFP-EPCs [31]. VEGF protein expression was significantly increased in CXCL12-EPCs compared to EPCs and GFPEPCs in vitro. It has been reported that the expression of CXCL12 and VEGF as well as the number of EPCs in blood strongly correlated with each other in ischemic patients $[48,49]$. Subacute administration of VEGF can promote angiogenesis in the ischemic penumbra and significantly improve neurological recovery in ischemic rats [50]. The combination of CXCL12 and VEGF enhanced angiogenesis more than the monotherapies under conditions of hypercholesterolemia [51], in line with the enhanced effects of CXCL12-EPC cell therapy over LVCXCL12 gene therapy and GFP-EPC cell therapy alone in protecting blood vessels, promoting the proliferation of NPCs in the SVZ, and the migration of OPCs in the perifocal area of the mouse brain in the weeks after ischemic brain injury. It has been shown both in tumor models [52] and in our previous work in a cell culture model [31] that the CXCL12/CXCR4 axis promotes the expression of VEGF both at the mRNA and protein levels, most likely through the Akt pathway. VEGF not only plays a key role in neuroprotection, angiogenesis, and neurogenesis, but also promotes oligodendrocyte maturation, which may improve the histological and functional outcomes through multiple mechanisms [5355]. The benefits observed with CXCL12 and CXCL12EPC treatment could be at least partially attributed to their increased VEGF expression.

One of the challenges of translating stem cell therapy into the clinical setting is the difficulty of tracking the stem cells in vivo at both cellular and molecular levels following an extended time course [56, 57]. In a smallsize animal experiment, we tested our hypothesis that cxcl12-engineered EPCs will show improved efficacy compared to unmodified EPCs. In the study, very few EPCs were observed at 4 weeks after transplantation, which suggested that the transplanted EPCs probably mainly function through the upregulation of multiple trophic factors, which has been demonstrated in a myocardial injury model [58]. Further study is warranted to follow the transplanted cells at smaller time intervals to gain better insight into their migration, differentiation, and localization fate. Superparamagnetic iron oxide nanoparticles as well as $\mathrm{I}^{125}$ isotopes have been successfully used in tracking stem cells in vivo [13, 59]. Further studies using such tracking means will better inform on the fate and potential mechanisms of function of the transplanted cells.

\section{Conclusion}

This study showed that cxcl12 engineering of EPCs resulted in better histological and functional outcomes in ischemic mice, even when they are transplanted at 1 week after pMCAO. These beneficial effects may be related to the protection of blood vessels and myelin sheath integrity, the promotion of angiogenesis and neurogenesis, and the enhancement of the proliferation and migration of OPCs during the 4 weeks after treatment. These data suggest that cxcl12 modification of EPCs is a promising strategy in the treatment of ischemic stroke with a wider treatment window during the post-acute phase after ischemic injury.

\section{Abbreviations \\ BDNF: Brain-derived neurotrophic factor; bFGF: Basic fibroblast growth factor; EPC: Endothelial progenitor cell; GFP: Green fluorescent protein; IOD: Integral optical density; MBP: Myelin basic protein; mNSS: Modified neurological severity score; NPC: Neural progenitor cell; OPC: Oligodendrocyte progenitor cell; PBS: Phosphate-buffered saline; PDGF: Platelet-derived growth factor; pMCAO: Permanent middle cerebral artery occlusion; SVZ: Subventricular zone; VEGF: Vascular endothelial growth factor}

\section{Funding}

This work was supported by the National Natural Science Foundation of China (81522015 and 81371305 to YW; 81471178 and 81771251 to G-YY; 81771244 to ZZ) and K. C. Wong Education Foundation (to G-YY).

\section{Availability of data and materials}

All data generated or analyzed during this study are included in the published article.

\section{Authors' contributions}

YL contributed to conception and design, provision of study material, collection and/or assembly of data, data analysis and interpretation, manuscript writing, and final approval of the manuscript. GT contributed to provision of study material and final approval of the manuscript. SC, WL, YM, YL, FY, ZZ and HT contributed to collection and/or assembly of data, and final approval of the manuscript. G-YY and YW contributed to conception and design, financial support, administrative support, provision of study material, data analysis and interpretation, manuscript writing, and final approval of manuscript.

\section{Ethics approval and consent to participate}

This procedure is supported by grant NSFC \#81522015 and is approved by the Bioethics Committee of the School of Biomedical Engineering, Shanghai Jiao

Tong University (\#2015002). All participants gave written informed consent.

\section{Competing interests}

The authors declare that they have no competing interests. 


\section{Publisher's Note}

Springer Nature remains neutral with regard to jurisdictional claims in published maps and institutional affiliations.

\begin{abstract}
Author details
'School of Biomedical Engineering and Shanghai Jiao Tong University, Affiliated Sixth People's Hospital, Shanghai Jiao Tong University, 1954 Hua Shan Road, Shanghai 200030, China. ${ }^{2}$ Department of Neurology, Ruijin Hospital, School of Medicine, Shanghai Jiao Tong University, Shanghai 200030, China
\end{abstract}

\section{Received: 30 November 2017 Revised: 8 March 2018}

Accepted: 10 April 2018 Published online: 11 May 2018

\section{References}

1. Broughton BRS, Reutens DC, Sobey CG. Apoptotic mechanisms after cerebral ischemia. Stroke. 2009;40:E331-9.

2. Lo EH, Moskowitz MA, Jacobs TP. Exciting, radical, suicidal-how brain cells die after stroke. Stroke. 2005;36:189-92.

3. Pantoni L, Garcia JH, Gutierrez JA. Cerebral white matter is highly vulnerable to ischemia. Stroke. 1996;27:1641-6.

4. Arai K, Lo EH. Experimental models for analysis of oligodendrocyte pathophysiology in stroke. Exp Transl Stroke Med. 2009;1:6.

5. Li Y, Chopp M, Jiang N, Yao F, Zaloga C. Temporal profile of in-situ DNA fragmentation after transient middle cerebral-artery occlusion in the rat. J Cerebr Blood Flow Metab. 1995;15:389-97.

6. Karki K, Knigh RA, Shen LH, Kapke A, Lu M, Li Y, Chopp M. Chronic brain tissue remodeling after stroke in rat: a 1-year multiparametric magnetic resonance imaging study. Brain Res. 2010;1360:168-76.

7. Prabhakaran S, Ruff I, Bernstein RA. Acute stroke intervention: a systematic review. JAMA. 2015;313:1451-62.

8. Asahara T, Murohara T, Sullivan A, Silver M, van der Zee R, Li T, Witzenbichler B, Schatteman G, Isner JM. Isolation of putative progenitor endothelial cells for angiogenesis. Science. 1997;275:964-7.

9. Sobrino T, Hurtado O, Moro MA, Rodriguez-Yanez M, Castellanos M, Brea D, Moldes O, Blanco M, Arenillas JF, Leira R, et al. The increase of circulating endothelial progenitor cells after acute ischemic stroke is associated with good outcome. Stroke. 2007;38:2759-64.

10. Yip HK, Chang LT, Chang WN, Lu CH, Liou CW, Lan MY, Liu JS, Youssef AA Chang HW. Level and value of circulating endothelial progenitor cells in patients after acute ischemic stroke. Stroke. 2008;39:69-74.

11. Tsai NW, Hung SH, Huang CR, Chang HW, Chang WN, Lee LH, Wang HC, Lin YJ, Lin WC, Cheng BC, et al. The association between circulating endothelial progenitor cells and outcome in different subtypes of acute ischemic stroke. Clin Chim Acta. 2014;427:6-10.

12. Zhang ZG, Zhang L, Jiang Q, Chopp M. Bone marrow-derived endothelial progenitor cells participate in cerebral neovascularization after focal cerebral ischemia in the adult mouse. Circ Res. 2002;90:284-8.

13. Li Q, Tang G, Xue S, He X, Miao P, Li Y, Wang J, Xiong L, Wang Y, Zhang C, et al. Silica-coated superparamagnetic iron oxide nanoparticles targeting of EPCs in ischemic brain injury. Biomaterials. 2013;34:4982-92.

14. Chen C, Lin X, Wang J, Tang G, Mu Z, Chen X, Xu J, Wang Y, Zhang Z, Yang GY. Effect of HMGB1 on the paracrine action of EPC promotes postischemic neovascularization in mice. Stem Cells. 2014;32:2679-89.

15. Fan YF, Shen FX, Frenzel T, Zhu W, Ye JQ, Liu JR, Chen YM, Su H, Young WL, Yang GY. Endothelial progenitor cell transplantation improves long-term stroke outcome in mice. Ann Neurol. 2010;67:488-97.

16. DApuzzo M, Rolink A, Loetscher M, Hoxie JA, ClarkLewis I, Melchers F, Baggiolini M, Moser B. The chemokine SDF-1, stromal cell-derived factor 1, attracts early stage $B$ cell precursors via the chemokine receptor CXCR4. Eur J Immunol. 1997:27:1788-93.

17. Petit I, Jin D, Rafii S. The SDF-1-CXCR4 signaling pathway: a molecular hub modulating neo-angiogenesis. Trends Immunol. 2007;28:299-307.

18. Kuliszewski MA, Kobulnik J, Lindner JR, Stewart DJ, Leong-Poi H. Vascular gene transfer of SDF-1 promotes endothelial progenitor cell engraftment and enhances angiogenesis in ischemic muscle. Mol Ther. 2011;19:895-902.

19. Li WL, Kohara H, Uchida Y, James JM, Soneji K, Cronshaw DG, Zou YR, Nagasawa T, Mukouyama YS. Peripheral nerve-derived CXCL12 and VEGF-A regulate the patterning of arterial vessel branching in developing limb skin. Dev Cell. 2013;24:359-71.
20. Toba Y, Tiong JD, Ma O, Wray S. CXCR4/SDF-1 system modulates development of $\mathrm{GnRH}-1$ neurons and the olfactory system. Dev Neurobiol. 2008;68:487-503.

21. Hagihara K, Zhang EE, Ke YH, Liu GF, Liu JJ, Rao Y, Feng GS. Shp2 acts downstream of SDF-1 alpha/CXCR4 in guiding granule cell migration during cerebellar development. Dev Biol. 2009;334:276-84.

22. Mithal DS, Banisadr G, Miller RJ. CXCL12 signaling in the development of the nervous system. J Neuroimmune Pharm. 2012;7:820-34.

23. Dziembowska M, Tham TN, Lau P, Vitry S, Lazarini F, Dubois-Dalcq M. A role for CXCR4 signaling in survival and migration of neural and oligodendrocyte precursors. Glia. 2005;50:258-69.

24. Maysami S, Nguyen D, Zobel F, Pitz C, Heine S, Hopfner M, Stangel M Modulation of rat oligodendrocyte precursor cells by the chemokine CXCL12. Neuroreport. 2006;17:1187-90.

25. Patel JR, McCandless EE, Dorsey D, Klein RS. CXCR4 promotes differentiation of oligodendrocyte progenitors and remyelination. Proc Natl Acad Sci U S A. 2010;107:11062-7.

26. Kadi L, Selvaraju R, de Lys P, Proudfoot AEl, Wells TNC, Boschert U. Differential effects of chemokines on oligodendrocyte precursor proliferation and myelin formation in vitro. J Neuroimmunol. 2006;174: $133-46$

27. Yamaguchi J, Kusano KF, Masuo O, Kawamoto A, Silver M, Murasawa S, Bosch-Marce M, Masuda H, Losordo DW, Isner JM, et al. Stromal cell-derived factor-1 effects on ex vivo expanded endothelial progenitor cell recruitment for ischemic neovascularization. Circulation. 2003;107:1322-8.

28. Zheng H, Dai T, Zhou BQ, Zhu JH, Huang H, Wang M, Fu GS. SDF-1 alpha/ CXCR4 decreases endothelial progenitor cells apoptosis under serum deprivation by PI3K/Akt/eNOS pathway. Atherosclerosis. 2008;201:36-42.

29. Shen X, Zhou Y, Bi X, Zhang J, Fu G, Zheng H. Stromal cell-derived factorlalpha prevents endothelial progenitor cells senescence and enhances reendothelialization of injured arteries via human telomerase reverse transcriptase. Cell Biol Int. 2015:39:962-71.

30. Li YN, Huang J, He XS, Tang GH, Tang YH, Liu YQ, Lin XJ, Lu YF, Yang GY, Wang YT. Postacute stromal cell-derived factor-1 alpha expression promotes neurovascular recovery in ischemic mice. Stroke. 2014;45:1822-9.

31. Chang $S$, Li Y, Yuan F, Qu M, Song Y, Zhang Z, Yang GY, Wang Y. Monomeric CXCL12 outperforms its dimeric and wild type variants in the promotion of human endothelial progenitor cells' function. Biochem Biophys Res Commun. 2017:488:303-10.

32. Steinberg GK, Kondziolka D, Wechsler LR, Lunsford LD, Coburn ML, Billigen JB, Kim AS, Johnson JN, Bates D, King B, et al. Clinical outcomes of transplanted modified bone marrow-derived mesenchymal stem cells in stroke: a phase 1/2a study. Stroke. 2016;47:1817-24.

33. He X, Li Y, Lu H, Zhang Z, Wang Y, Yang GY. Netrin-1 overexpression promotes white matter repairing and remodeling after focal cerebral ischemia in mice. J Cereb Blood Flow Metab. 2013;33:1921-7.

34. Cheng CC, Chang SJ, Chueh YN, Huang TS, Huang PH, Cheng SM, Tsai TN, Chen JW, Wang HW. Distinct angiogenesis roles and surface markers of early and late endothelial progenitor cells revealed by functional group analyses. BMC Genomics. 2013;14:182.

35. Shi W, Nie DK, Jin GH, Chen WW, Xia L, Wu XJ, Su X, Xu XD, Ni LC, Zhang XA, et al. BDNF blended chitosan scaffolds for human umbilical cord MSC transplants in traumatic brain injury therapy. Biomaterials. 2012;33:3119-26.

36. Huang J, Li YN, Tang YH, Tang GH, Yang GY, Wang YT. CXCR4 antagonist AMD3100 protects blood-brain barrier integrity and reduces inflammatory response after focal ischemia in mice. Stroke. 2013;44:190-7.

37. Chen JL, Li Y, Wang L, Zhang ZG, Lu DY, Lu M, Chopp M. Therapeutic benefit of intravenous administration of bone marrow stromal cells after cerebral ischemia in rats. Stroke. 2001:32:1005-11.

38. Li YN, Tang GH, Liu YQ, He XS, Huang J, Lin XJ, Zhang ZJ, Yang GY, Wang YT. CXCL12 gene therapy ameliorates ischemia-induced white matter injury in mouse brain. Stem Cell Transl Med. 2015:4:1122-30.

39. Thored P, Wood J, Arvidsson A, Cammenga J, Kokaia Z, Lindvall O. Long-term neuroblast migration along blood vessels in an area with transient angiogenesis and increased vascularization after stroke. Stroke. 2007;38: 3032-9

40. Kokovay E, Goderie S, Wang Y, Lotz S, Lin G, Sun Y, Roysam B, Shen Q Temple S. Adult SVZ lineage cells home to and leave the vascular niche via differential responses to SDF1/CXCR4 signaling. Cell Stem Cell. 2010;7:163-73. 
41. Fallon J, Reid S, Kinyamu R, Opole I, Opole R, Baratta J, Korc M, Endo TL, Duong A, Nguyen $\mathrm{G}$, et al. In vivo induction of massive proliferation, directed migration, and differentiation of neural cells in the adult mammalian brain. Proc Natl Acad Sci U S A. 2000:97:14686-91.

42. Ming GL, Song HJ. Adult neurogenesis in the mammalian central nervous system. Annu Rev Neurosci. 2005;28:223-50.

43. Irvine KA, Blakemore WF. Remyelination protects axons from demyelinationassociated axon degeneration. Brain. 2008;131:1464-77.

44. Kinnunen KM, Greenwood R, Powell JH, Leech R, Hawkins PC, Bonnelle V, Patel MC, Counsell SJ, Sharp DJ. White matter damage and cognitive impairment after traumatic brain injury. Brain. 2011;134:449-63.

45 Rosell A, Morancho A, Navarro-Sobrino M, Martinez-Saez E, HernandezGuillamon M, Lope-Piedrafita S, Barcelo V, Borras F, Penalba A, Garcia-Bonilla L, et al. Factors secreted by endothelial progenitor cells enhance neurorepair responses after cerebral ischemia in mice. PLoS One. 2013:8:e73244.

46 Bath KG, Akins MR, Lee FS. BDNF control of adult SVZ neurogenesis. Dev Psychobiol. 2012;54:578-89.

47 Rivers LE, Young KM, Rizzi M, Jamen F, Psachoulia K, Wade A, Kessaris $\mathrm{N}$, Richardson WD. PDGFRA/NG2 glia generate myelinating oligodendrocytes and piriform projection neurons in adult mice. Nat Neurosci. 2008;11:1392-401.

48 Smythe J, Fox A, Fisher N, Frith E, Harris AL, Watt SM. Measuring angiogenic cytokines, circulating endothelial cells, and endothelial progenitor cells in peripheral blood and cord blood: VEGF and CXCL12 correlate with the number of circulating endothelial progenitor cells in peripheral blood. Tissue Eng Part C Methods. 2008;14:59-67.

49 Bogoslovsky T, Spatz M, Chaudhry A, Maric D, Luby M, Frank J, Warach S, Stroke NNH. Stromal-derived factor-1 alpha correlates with circulating endothelial progenitor cells and with acute lesion volume in stroke patients. Stroke. 2011;42:618-25.

50 Zhang ZG, Zhang L, Jiang Q, Zhang RL, Davies K, Powers C, van Bruggen N, Chopp M. VEGF enhances angiogenesis and promotes blood-brain barrier leakage in the ischemic brain. J Clin Invest. 2000;106:829-38.

51 Jin FY, Hagemann N, Schafer ST, Brockmeier U, Zechariah A, Hermann DM. SDF-1 restores angiogenesis synergistically with VEGF upon LDL exposure despite CXCR4 internalization and degradation. Cardiovasc Res. 2013:100:481-91.

52 Liang Z, Brooks J, Willard M, Liang K, Yoon Y, Kang S, Shim H. CXCR4/ CXCL12 axis promotes VEGF-mediated tumor angiogenesis through Akt signaling pathway. Biochem Biophys Res Commun. 2007;359:716-22.

53 Jin KL, Zhu YH, Sun YJ, Mao XO, Xie L, Greenberg DA. Vascular endothelial growth factor (VEGF) stimulates neurogenesis in vitro and in vivo. Proc Natl Acad Sci U S A. 2002;99:11946-50.

54 Sun YJ, Jin KL, Xie L, Childs J, Mao XO, Logvinova A, Greenberg DA. VEGFinduced neuroprotection, neurogenesis, and angiogenesis after focal cerebral ischemia. J Clin Investig. 2003;111:1843-51.

55 Kim HM, Hwang DH, Lee JE, Kim SU, Kim BG. Ex vivo VEGF delivery by neural stem cells enhances proliferation of glial progenitors, angiogenesis, and tissue sparing after spinal cord injury. PLoS One. 2009;4:e4987.

56 Spiriev T, Sandu N, Schaller B. Molecular imaging and tracking stem cells in neurosciences. Methods Mol Biol. 2013;1052:195-201.

57 Sandu N, Chowdhury T, Schaller B. Molecular imaging for stem cell therapy in the brain. Stem Cell Res Ther. 2015;6:252.

58 Cho HJ, Lee N, Lee JY, Choi YJ, Li M, Wecker A, Jeong JO, Curry C, Qin G, Yoon YS. Role of host tissues for sustained humoral effects after endothelial progenitor cell transplantation into the ischemic heart. J Exp Med. 2007:204:3257-69

59 Tang Y, Zhang C, Wang J, Lin X, Zhang L, Yang Y, Wang Y, Zhang Z, Bulte JW, Yang GY. MRI/SPECT/fluorescent tri-modal probe for evaluating the homing and therapeutic efficacy of transplanted mesenchymal stem cells in a rat ischemic stroke model. Adv Funct Mater. 2015;25:1024-34.

Ready to submit your research? Choose BMC and benefit from:

- fast, convenient online submission

- thorough peer review by experienced researchers in your field

- rapid publication on acceptance

- support for research data, including large and complex data types

- gold Open Access which fosters wider collaboration and increased citations

- maximum visibility for your research: over $100 \mathrm{M}$ website views per year

At BMC, research is always in progress.

Learn more biomedcentral.com/submissions 